\title{
The Biopsychosocial Model 25 Years Later: Principles, Practice, and Scientific Inquiry
}

\author{
Francesc Borrell-Carrió, $M D^{1}$ \\ Antbony L. Sucbman MD ${ }^{2,3}$ \\ Ronald M. Epstein MD \\ 'Department of Medicine, University of \\ Barcelona, CAP Cornellà, Catalonian \\ Institute of Health (ICS), Cornellà de \\ Llobregat, Spain \\ ${ }^{2}$ Relationship Centered Health Care, \\ Rochester, NY \\ ${ }^{3}$ Department of Medicine, University of \\ Rochester School of Medicine and Dentistry, \\ Rochester, NY \\ ${ }^{4}$ Department of Family Medicine, \\ University of Rochester School of Medicine \\ and Dentistry, Rochester, NY

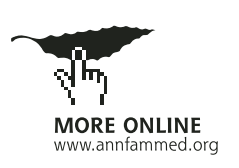

\section{CORRESPONDING AUTHOR}

Francesc Borrell-Carrió, MD Department of Medicine University of Barcelona CAP Cornellà, Catalonian Institute of Health (ICS)

C/Bellaterra 39

08940 Cornellà de Llobregat, Spain

12902fbc@comb.es

\begin{abstract}
The biopsychosocial model is both a philosophy of clinical care and a practical clinical guide. Philosophically, it is a way of understanding how suffering, disease, and illness are affected by multiple levels of organization, from the societal to the molecular. At the practical level, it is a way of understanding the patient's subjective experience as an essential contributor to accurate diagnosis, health outcomes, and humane care. In this article, we defend the biopsychosocial model as a necessary contribution to the scientific clinical method, while suggesting 3 clarifications: (1) the relationship between mental and physical aspects of health is complex-subjective experience depends on but is not reducible to laws of physiology; (2) models of circular causality must be tempered by linear approximations when considering treatment options; and (3) promoting a more participatory clinicianpatient relationship is in keeping with current Western cultural tendencies, but may not be universally accepted. We propose a biopsychosocial-oriented clinical practice whose pillars include (1) self-awareness; (2) active cultivation of trust; (3) an emotional style characterized by empathic curiosity; (4) self-calibration as a way to reduce bias; (5) educating the emotions to assist with diagnosis and forming therapeutic relationships; (6) using informed intuition; and (7) communicating clinical evidence to foster dialogue, not just the mechanical application of protocol. In conclusion, the value of the biopsychosocial model has not been in the discovery of new scientific laws, as the term "new paradigm" would suggest, but rather in guiding parsimonious application of medical knowledge to the needs of each patient.
\end{abstract}

Ann Fam Med 2004;2:576-582. DOI: 10.1370/afm.245.

\section{GEORGE ENGEL'S LEGACY}

7 he late George Engel believed that to understand and respond adequately to patients' suffering - and to give them a sense of being understood-clinicians must attend simultaneously to the biological, psychological, and social dimensions of illness. He offered a holistic alternative to the prevailing biomedical model that had dominated industrialized societies since the mid-20th century. ${ }^{1}$ His new model came to be known as the biopsychosocial model. He formulated his model at a time when science itself was evolving from an exclusively analytic, reductionistic, and specialized endeavor to become more contextual and cross-disciplinary. ${ }^{2-4}$ Engel did not deny that the mainstream of biomedical research had fostered important advances in medicine, but he criticized its excessively narrow (biomedical) focus for leading clinicians to regard patients as objects and for ignoring the possibility that the subjective experience of the patient was amenable to scientific study. Engel championed his ideas not only as a scientific proposal, but also as a fundamental ideology that tried to reverse the dehumanization of medicine and disempowerment of patients (Table 1). His model struck a resonant chord with those sectors of the medical profession that wished to bring more empathy and compassion into medical practice.

In this article we critically examine and update 3 areas in which the biopsychosocial model was offered as a "new medical paradigm" ${ }^{15,6}$ : (1) a 


\section{Table 1. Engel's Critique of Biomedicine}

1. A biochemical alteration does not translate directly into an illness. The appearance of illness results from the interaction of diverse causal factors, including those at the molecular, individual, and social levels. And the converse, psychological alterations may, under certain circumstances, manifest as illnesses or forms of suffering that constitute health problems, including, at times, biochemical correlates

2. The presence of a biological derangement does not shed light on the meaning of the symptoms to the patient, nor does it necessarily infer the attitudes and skills that the clinician must have to gather information and process it well

3. Psychosocial variables are more important determinants of susceptibility, severity, and course of illness than had been previously appreciated by those who maintain a biomedical view of illness

4. Adopting a sick role is not necessarily associated with the presence of a biological derangement

5. The success of the most biological of treatments is influenced by psychosocial factors, for example, the so-called placebo effect

6. The patient-clinician relationship influences medical outcomes, even if only because of its influence on adherence to a chosen treatment

7. Unlike inanimate subjects of scientific scrutiny, patients are profoundly influenced by the way in which they are studied, and the scientists engaged in the study are influenced by their subjects tic and reductionistic orientation of medical thinking. According to these principles, anything that could not be objectively verified and explained at the level of cellular and molecular processes was ignored or devalued. The main focus of this criticism-a cold, impersonal, technical, biomedically-oriented style of clinical practice-may not have been so much a matter of underlying philosophy, but discomfort with practice that neglected the human dimension of suffering. His seminal 1980 article on the clinical application of the biopsychoso- world view that would include the patient's subjective experience alongside objective biomedical data, (2) a model of causation that would be more comprehensive and naturalistic than simple linear reductionist models, and (3) a perspective on the patient-clinician relationship that would accord more power to the patient in the clinical process and transform the patient's role from passive object of investigation to the subject and protagonist of the clinical act. We will also explore the interface between the biopsychosocial model and evidence-based medicine.

\section{DUALISM, REDUCTIONISM, AND THE DETACHED OBSERVER}

In advancing the biopsychosocial model, Engel was responding to 3 main strands in medical thinking that he believed were responsible for dehumanizing care. First, he criticized the dualistic nature of the biomedical model, with its separation of body and mind (which is popularly, but perhaps inaccurately, traced to Descartes). ${ }^{7,8}$ This conceptualization (further discussed in the supplemental appendix, available online at http://

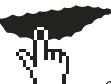

www.annfammed.org/cgi/content/full/2/6/576/

DC1) included an implicit privileging of the former as more "real" and therefore more worthy of a scientific clinician's attention. Engel rejected this view for encouraging physicians to maintain a strict separation between the body-as-machine and the narrative biography and emotions of the person-to focus on the disease to the exclusion of the person who was suffering — without building bridges between the two realms. His research in psychosomatics pointed toward a more integrative view, showing that fear, rage, neglect, and attachment had physiologic and developmental effects on the whole organism.

Second, Engel criticized the excessively materialis- cial model ${ }^{5}$ examines the case of a man with chest pain whose arrhythmia was precipitated by a lack of caring on the part of his treating physician.

The third element was the influence of the observer on the observed. Engel understood that one cannot understand a system from the inside without disturbing the system in some way; in other words, in the human dimension, as in the world of particle physics, one cannot assume a stance of pure objectivity. In that way, Engel provided a rationale for including the human dimension of the physician and the patient as a legitimate focus for scientific study.

Engel's perspective is contrasted with a so-called monistic or reductionistic view, in which all phenomena could be reduced to smaller parts and understood as molecular interactions. Nor did he endorse a holistic-energetic view, many of whose adherents espouse a biopsychosocial philosophy; these views hold that all physical phenomena are ephemeral and controllable by the manipulation of healing energies. Rather, in embracing Systems Theory, ${ }^{2}$ Engel recognized that mental and social phenomena depended upon but could not necessarily be reduced to (ie, explained in terms of) more basic physical phenomena given our current state of knowledge. He endorsed what would now be considered a complexity view, ${ }^{9}$ in which different levels of the biopsychosocial hierarchy could interact, but the rules of interaction might not be directly derived from the rules of the higher and lower rungs of the biopsychosocial ladder. Rather, they would be considered emergent properties that would be highly dependent on the persons involved and the initial conditions with which they were presented, much as large weather patterns can depend on initial conditions and small influences. ${ }^{9}$ This perspective has guided decades of research seeking to elucidate the nature of these interactions. 


\section{COMPLEXITY SCIENCE: CIRCULAR AND STRUCTURAL CAUSALITY}

Engel objected to a linear cause-effect model to describe clinical phenomena. Clinical reality is far more complex. For example, although genetics may have a role in causing schizophrenia, no clinician would ignore the sociologic factors that might unleash or contain the manifestations of the illness.

\section{Complexity and Causality}

Few morbid conditions could be interpreted as being of the nature "one microbe, one illness"; rather, there are usually multiple interacting causes and contributing factors. Thus, obesity leads to both diabetes and arthritis; both obesity and arthritis limit exercise capacity, adversely affecting blood pressure and cholesterol levels; and all of the above, except perhaps arthritis, contribute to both stroke and coronary artery disease. Some of the effects (depression after a heart attack or stroke) can then become causal (greater likelihood of a second similar event). Similar observations can be made about predictors of relapse in schizophrenia. These observations set the stage for models of circular causality, which describes how a series of feedback loops sustain a specific pattern of behavior over time..$^{10-13}$ Complexity science is an attempt to understand these complex recursive and emergent properties of systems ${ }^{14,15}$ and to find interrelated proximal causes that might be changed with the right set of interventions (family support and medications for schizophrenia, depression screening and cholesterol level reduction after a heart attack).

\section{Structural Causality}

In contrast to the circular view, structural causality describes a hierarchy of unidirectional cause-effect relationships-necessary causes, precipitants, sustaining forces, and associated events. ${ }^{16}$ For instance, a necessary cause for tuberculosis is a mycobacterium, precipitants can be a low body temperature, and a sustaining force a low caloric intake. Complexity science can facilitate understanding of a clinical situation, but most of the time a structural model is what guides practical action. For example, if we think that Mr. J is hypertensive because he consumes too much salt, has a stressful job, poor social supports, and an overresponsible personality type, following a circular causal model, possibly all of these factors are truly contributory to his high blood pressure. But, when we suggest to him that he take an antihypertensive medication, or that he consume less salt, or that he take a stress-reduction course, or that he see a psychotherapist to reduce his sense of guilt, we are creating an implicit hierarchy of causes: Which cause has the greatest likely contribution to his high blood pressure? Which would be most responsive to our actions? What is the added value of this action, after having done others? Which strategy will give the greatest result with the least harm and with the least expenditure of resources?

\section{Interpretations, Language, and Causality}

Causal attributions have the power to create reality and transform the patient's view of his/her own world. ${ }^{17} \mathrm{~A}$ physician who listens well might agree when a patient worries that a family argument precipitated a myocardial infarction; although this interpretation may have meaning to the patient, it is inadequate as a total explanation of why the patient suffered a myocardial infarction. The attribution of causality can be used to blame the patient for his or her illness ("If only he had not smoked so much...."), and also may have the power of suggestion and might actually worsen the patient's condition ("Every time there is a fight, your dizziness worsens, don't you see?").

\section{TOWARD A RELATIONSHIP-CENTERED MODEL}

Power and Emotions in the Clinical Relationship Patient-centered, relationship-centered, and client-centered approaches ${ }^{18-24}$ propose that arriving at a correct biomedical diagnosis is only part of the clinician's task; they also insist on interpreting illness and health from an intersubjective perspective by giving the patient space to articulate his or her concerns, finding out about the patient's expectations, and exhorting the health professional to show the patient a human face. These approaches represent movement toward an egalitarian relationship in which the clinician is aware of and careful with his or her use of power.

This "dialogic" model suggests that the reality of each person is not just interpreted by the physician, but actually created and recreated through dialogue ${ }^{25-31}$; individual identities are constructed in and maintained through social interaction. ${ }^{32}$ The physician's task is to come to some shared understanding of the patient's narrative with the patient. Such understanding does not imply uncritical acceptance of whatever the patient believes or hypothesizes, but neither does it allow for the uncritical negation of the patient's perspective, as so frequently occurs, for example, when patients complain of symptoms that physicians cannot explain. ${ }^{33,34}$ The patient's story is simultaneously a statement about the patient's life, the here-and-now enactment of his life trajectory, and data upon which to formulate a diagnosis and treatment plan.

Underlying the analysis of power in the clinical relationship is the issue of how the clinician handles the 
strong emotions that characterize everyday practice. On the one hand, there is a reactive clinical style, in which the clinician reacts swiftly to expressions of hostility or distrust with denial or suppression. In contrast, a proactive clinical style, characterized by a mindful openness to experience, might lead the clinician to accept the patient's expressions with aplomb, using the negative feelings to strengthen the patient-clinician relationship. ${ }^{35}$ The clinician must acknowledge and then transcend the tendency to label patients as "those with whom I get along well" or "difficult patients." By removing this set of judgments, true empathy can devolve from a sense of solidarity with the patient and respect for his or her humanity, leading to tolerance and understanding. ${ }^{18}$ Thus, in addition to the moral imperative to treat the patient as a person, there is a corresponding imperative for the physician to care for and deepen knowledge of himself or herself. ${ }^{35,36} \mathrm{Without}$ a sufficient degree of self-understanding, it is easy for the physician to confuse empathy with the projection of his or her needs onto the patient.

\section{Implications for Autonomy}

Most patients desire more information from their physicians, fewer desire direct participation in clinical decisions, and very few want to make important decisions without the physician's advice and consultation with their family members. ${ }^{37-40}$ This does not mean that patients wish to be passive, even the seriously ill and the elderly. ${ }^{41}$ In some cases, however, clinicians unwittingly impose autonomy on patients. ${ }^{19,42,43}$ Making a reluctant patient assume too much of the burden of knowledge about an illness and decision making, without the advice from the physician and support from his or her family, can leave the patient feeling abandoned and deprived of the physician's judgment and expertise..$^{42}$ The ideal, then, might be "autonomy in relation" —an informed choice supported by a caring relationship. ${ }^{19}$ The clinician can offer the patient the option of autonomy ${ }^{41}$ while considering the possibility that the patient might not want to know the whole truth and wish to exercise the right to delegate decisions to family members. ${ }^{40,44}$

\section{The Social Milieu}

There is an ecological dimension of each encounter-it is not just between patient and physician, but rather an expression of social norms. ${ }^{45}$ Sometimes clinicians face a dilemma: can or should a private clinical relationship between patient and physician be a vehicle for social transformation? Or, should the relationship honor and conform to the cultural norms of patients? ${ }^{19}$ Our view is that adaptation normally should occur before transformation - the physician must first understand and accommodate to the patient's values and cultural norms before trying to effect change. Otherwise, the relationship becomes a political battleground and the focus of a process to which the patient has not consented and may not desire. This debate, however, becomes much more difficult in situations in which patients have suffered abusefor example domestic violence or victims of torture. ${ }^{46}$ In those cases, not trying to remedy the social injustices that resulted in the patient seeking care may interfere with the formation of a trusting relationship. The physician may be tempted to effect a social transformation in these cases, for example, to advise the patient to leave an abusive situation, even though the patient may state that she only wants care for the bruises. Premature advice may interfere with enabling the patient to be the agent of change, however. Stopping short of attempting to transform social relationships until the patient has given consent should not be interpreted as indifference to, acceptance of, or complicity in such situations; rather, it should be viewed as a prudent course of action that will ultimately be validating and empowering.

\section{Caring, Paternalism, and Empathy}

Taking Engel's view, perhaps it is not paternalism that is the problem but practicing as a cold technician rather than a caring healer. ${ }^{47,48}$ The physician who sees his or her role as nothing more than a technical adviser can regard empathy as a useless effort that has no influence on clinical decisions, or, worse, a set of linguistic tricks to get the patient to comply with treatment. Because it is entirely possible to advocate for shared decision making without challenging the notion of the cold technician, we propose to move the emphasis to an approach that emphasizes human warmth, understanding, generosity, and caring.

\section{THE BIOPSYCHOSOCIAL MODEL AND RELATIONSHIP-CENTERED CARE}

The practical application of the biopsychosocial model, which we will call biopsychosocially oriented clinical practice does not necessarily evolve from the constructs of interactional dualism or circular causality. Rather, it may be that the content and emotions that constitute the clinician's relationship with the patient are the fundamental principles of biopsychosocial-oriented clinical practice, which then inform the manner in which the physician exercises his or her power. The models of relationship that have tended to appear in the medical literature, with a few notable exceptions, ${ }^{19}$ have perhaps focused too much on an analysis of power and too little on the underlying emotional climate of the clinical relationship. For this reason, we suggest a reformulation of some of the basic principles of the biopsychosocial model according to the emotional tone that engraves the relationship with such characteristics as caring, trustwor- 
thiness, and openness. ${ }^{49,50}$ Some principles of biopsychosocial-oriented clinical practice are outlined below.

\section{Calibrating the Physician}

The biopsychosocial model calls for expanding the number and types of habits to be consciously learned and objectively monitored to maintain the centrality of the patient. ${ }^{51}$ The physician is in some ways like a musical instrument that needs to be calibrated, tuned, and adjusted to perform adequately. ${ }^{36}$ The physician's skills should be judged on their ability to produce greater health or to relieve the patient's suffering-whether they include creating an adequate emotional tone, gathering an accurate history, or distinguishing between what the patient needs and what the patient says he or she wants. In that regard, a clinical skill includes the ethical mandate not only to find out what concerns the patient, but to bring the physician's agenda to the table and influence the patient's behavior. Sometimes doing so may include uncovering psychosocial correlates of otherwise unexplained somatic symptoms (such as ongoing abuse or alcoholism) to break the cycle of medicalization and iatrogenesis. ${ }^{33}$ To abandon this obligation, in our view, is breaking an implicit social contract between physicians and society. This deliberative and sometimes frankly physician-centered approach has its perils, however. The physician must be capable of an ongoing self-audit simply because his or her performance is never the same from moment to moment. Weick and Sutcliffe ${ }^{52}$ regard this constant vigilance as a fundamental requirement for professions that require high reliability in the face of unexpected events. Mindfulness - the habits of attentive observation, critical curiosity, informed flexibility, and presence-underlies the physician's ability to self-monitor, be vigilant, and respond with compassion. ${ }^{35,53,54}$

\section{Creating Trust}

The expert clinician considers explicitly, as a core skill, the achievement in the encounter of an emotional tone conducive to a therapeutic relationship. For that reason, all consultations might be judged on the basis of cordiality, optimism, genuineness, and good humor. By receiving a hostile patient with respect, ${ }^{55}$ it clarifies for the clinician that the patient's emotions are the patient's - and not the physician's - and also sets the stage for the patient to reflect as well. Similarly, the physician must know how to recognize and when to express his or her own emotions, sometimes setting limits and boundaries in the interest of preserving a functional relationship.

\section{Cultivating Curiosity}

The next step in the application of clinical evidence to medical care is the cultivation of curiosity. Thus, cultivated naïvete ${ }^{56}$ might be considered one of the fundamental habits characteristic of expert practitioners. Another aspect of this emotional tone is an empathic curiosity about the patient as person. Empathic curiosity allows the clinician to maintain an open mind and not to consider that any case is ever closed. If the patient does not surprise us today, perhaps he or she will tomorrow. We have described this capacity using the term, beginner's mind. ${ }^{35,57}$ It is the capacity for expecting the unexpected, just as if the physician were another clinician seeing the patient for the first time. There is also an ethical component of this emotional tone-there are no "good" or "bad" patients, nor are there "interesting" and "boring" diseases. Patients should not have to legitimize their suffering by describing illnesses that make the clinician feel comfortable or confident. ${ }^{58}$

\section{Recognizing Bias}

The grounding of medical decisions based on scientific evidence while also integrating the clinician's professional experience is now a well-accepted tenet of the founders of the evidence-based medicine movement. ${ }^{59}$ The method for incorporation of experience, however, has been less well described than the method for judging the quality of scientific evidence. For example, clinicians should learn how their decisions might be biased by the race and sex of the patient, among other factors, ${ }^{51}$ and also the tendency to close the case prematurely to rid oneself of the burden of attempting to solve complex problems. ${ }^{60}$

\section{Educating the Emotions}

There are methods for emotional education, just as there are for learning new knowledge and skills. ${ }^{35}$ Tolerance of uncertainty, for example, is amenable to observation and calibration-making decisions in the absence of complete information is a characteristic of an expert practitioner, in contrast to the technician who views his role as simply following protocols.

\section{Using Informed Intuition}

The role of intuition is central. Just as Polanyi and Schön maintain that professional competence is based in tacit, rather than explicit, knowledge ${ }^{61,62}$ expertise often is manifest in insights that are difficult to track on a strictly cognitive level. If a clinician, encountering a situation in which he normally would use a particular treatment, has the intuition, for a reason that has not yet become clear, that treatment might not be the best for this particular patient, we suggest, rather than considering it a feeling from nowhere that might be discarded, perhaps the intuition can later be traced to a set of concrete observations about the patient that were not easy for the clinician to describe at the time. Because these observations often are manifest only when cases are reviewed after the fact does not diminish the ethical 
obligation that the clinician use all of his or her capabilities, not only those which can be readily explained.

\section{Communicating Clinical Evidence}

Evidence should be communicated in terms the patient can understand, in small digestible pieces, at a rate at which it can be assimilated. Information overload may have two effects-reduction in comprehension and increasing the emotional distance between physician and patient. Communication of clinical evidence should foster understanding, not simply answers. ${ }^{63}$

\section{FURTHER DEVELOPMENT OF THE BIOPSYCHOSOCIAL MODEL}

George Engel formulated the biopsychosocial model as a dynamic, interactional, but dualistic view of human experience in which there is mutual influence of mind and body. We add to that model the need to balance a circular model of causality with the need to make linear approximations (especially in planning treatments) and the need to change the clinician's stance from objective detachment to reflective participation, thus infusing care with greater warmth and caring. The biopsychosocial model was not so much a paradigm shift-in the sense of a crisis of the scientific method in medicine or the elaboration of new scientific laws-as it was an expanded (but nonetheless parsimonious) application of existing knowledge to the needs of each patient.

In the 25 years that have elapsed since Engel first proposed the biopsychosocial model, two new intellectual trends have emerged that could make it even more robust. First, we can move beyond the problematic issue of mind-body duality by recognizing that knowledge is socially constructed. To some extent, such categories as "mind" or "body" are of our own creation. They are useful to the extent that they focus our thinking and action in helpful ways (eg, they contribute to health, well-being, and efficient use of resources), but when taken too literally, they can also entrap and limit us by creating boundaries that need not exist. By maintaining what William James called "fragile" categories, ${ }^{64}$ we can alter or dispose of categories as new evidence accumulates and when there is a need to engage in flexible, out-of-the-box thinking.

Second, we can move beyond the multidimensional and multifactorial linear thinking to consider complexity theory as a more adequate model for understanding causality, dualism, and participation in care. Complexity theory shows how, in open systems, it is often impossible to know all of the contributors to and influences on particular health outcomes. By describing the ways in which systems tend to self-organize, it provides guideposts to inform the clinician's actions. It also buf- fers the tendency to impose unrealistic expectations that one can know and control all of these contributors and influences. ${ }^{65}$

George Engel's most enduring contribution was to broaden the scope of the clinician's gaze. His biopsychosocial model was a call to change our way of understanding the patient and to expand the domain of medical knowledge to address the needs of each patient. It is perhaps the transformation of the way illness, suffering, and healing are viewed that may be Engel's most durable contribution.

To read or post commentaries in response to this article, see it online at http://www.annfammed.org/cgi/content/full/2/6/576.

Key words: Biopsychosocial model; clinical practice patterns; personal autonomy; empathy; communication; education

Submitted September 25, 2003; submitted, revised, January 28, 2004; accepted February 10, 2004.

Acknowledgments: The following people have provided important critiques of this article. We thankfully acknowledge their contributions, but do not infer that they take responsibility for the content of the article: Drs. Rogelio Altisent, Lucy M. Candib, Jordi Cebrià, José Corrales, Blas Coscollar, Javier García-Campayo, Salvador García-Sánchez, Diego Gracia, Maria León, Susan McDaniel, Fernando Orozco, Vicente Ortún, Timothy Quill, Roger Ruiz, Jorge Tizón, and Lyman Wynne.

\section{References}

1. Engel $G$. The need for a new medical model: a challenge for biomedicine. Science. 1977;196:129-136.

2. von Bertanlaffy L. Perspectives on General System Theory. New York, NY: George Braziller, Inc; 1975.

3. Kiel LD, Elliot E. Chaos Theory in the Social Sciences. Ann Arbor, Mich: University of Michigan Press; 1996.

4. Minuchin S, Rosman BL, Baker L. Psychosomatic Families. Cambridge: Harvard University Press; 1978.

5. Engel G. The clinical appplication of the biopsychosocial model. Am J Psychiatry. 1980;137:535-544.

6. Engel GL. How much longer must medicine's science be bounded by a seventeenth century world view? In: White KL, ed. The Task of Medicine: Dialogue at Wickenburg. Menlo Park, Calif: The Henry Kaiser Family Foundation; 1988:113-136.

7. Brown TM. Cartesian dualism and psychosomatics. Psychosomatics. 1989;30:322-331.

8. Damasio AR. Descartes' Error. New York, NY: Putnam's Sons; 1994.

9. Plsek P. Appendix B: Redesigning health care with insights from the science of complex adaptive systems. In: Institute of Medicine. Committee on Quality of Health Care in America. Crossing the Quality Chasm: A New Health Care System for the 21st Century. Washington, DC: National Academies Press; 2001:322-335.

10. Mackie JL. Causes and conditions. Amer Philosoph Q. 1965;2:245-264.

11. Mackie JL. The Cement of the Universe. A Study of Causation. Oxford UK: Oxford University Press; 1974.

12. Bateson G. Steps to an Ecology of Mind: A Revolutionary Approach to Man's Understanding of Himself. New York, NY: Ballantine Books; 1972.

13. Simon FB, Stierlin H, Wynne LC. Circularity/recursiveness/circular causality. The language of family therapy. In: A Systemic Vocabulary and Sourcebook. New York, NY: Family Process Press; 1985:37-39. 
14. Fraser SW, Greenhalgh T. Coping with complexity: educating for capability. BMJ. 2001; 323:799-803.

15. Miller WL, Crabtree BF, McDaniel R, Stange KC. Understanding change in primary care practice using complexity theory [see comments]. J Fam Pract. 1998; 46:369-376.

16. Sackett DL, Haynes RB, Tugwell P, Guyatt GH. Clinical Epidemiology: A Basic Science for Clinical Medicine. Boston, Mass: Little Brown and Co; 1992.

17. Kirmayer LJ. Mind and body as metaphors: hidden values in biomedicine. In: Lock M, Gordon DR, eds. Biomedicine Examined. Boston, Mass: Kluwer Academic Publishers; 1988:57-93.

18. Entralgo PL. Doctor and Patient. New York, NY: McGraw-Hill Book Company; 1969.

19. Candib LM. Medicine and the Family: A Feminist Perspective. New York NY: Basic Books; 1995.

20. Tresolini C, Pew-Fetzer Task Force. Health Professions Education and Relationship-Centered Care. San Francisco, Calif: Pew Health Professions Commission; 1994.

21. Mead N, Bower P. Measuring patient-centredness: a comparison of three observation-based instruments. Patient Educ Couns. 2000;39:71-80.

22. Putnam SS, Lipkin M. The patient-centered interview: research support. In: Lipkin M, Putnam SM, Lazare A. The Medical Interview. New York, NY: Springer-Verlag; 1995.

23. Stewart M. Towards a global definition of patient centered care. BMJ. $2001 ; 322: 444-445$

24. Tizón J. Psychological Components of Medical Practice. Barcelona: Doyma; 1989

25. Bartz R. Beyond the biopsychosocial model. New approaches to doctor-patient interactions. J Fam Pract. 1999;48:601-607

26. Habermas J. The Theory of Communicative Action: Volume I. Reason and the Rationalization of Society. Boston, Mass: Beacon; 1984.

27. Frank AW. The Wounded Storyteller. Chicago, III: The University of Chicago Press; 1995.

28. Borkan JM, Quirk M, Sullivan M. Finding meaning after the fall: injury narratives from elderly hip fracture patients. Soc Sci Med. 1991;33:947-957.

29. Hunter KM. Doctors' Stories: The Narrative Structure of Medical Knowledge. Princeton, NJ: Princeton University Press; 1991.

30. Jones $\mathrm{AH}$. Narrative based medicine: narrative in medical ethics. BMJ. 1999; 1999;318:253-256.

31. Kleinman AM. The Illness Narratives: Suffering, Healing, and the Human Condition. New York, NY: Basic Books; 1988.

32. Mead GH. Mind, Self and Society. Chicago, III: The University of Chicago Press; 1962

33. Epstein RM, Quill TE, McWhinney IR. Somatization reconsidered: incorporating the patient's experience of illness. Arch Int Med. $1999 ; 159: 215-222$

34. Salmon P, Peters S, Stanley I. Patients' perceptions of medical explanations for somatisation disorders: qualitative analysis. BMJ. $1999 ; 318: 372-376$

35. Epstein RM. Mindful practice. JAMA. 1999;282:833-839.

36. Novack DH, Suchman AL, Clark W, Epstein RM, Najberg E, Kaplan C. Calibrating the physician: personal awareness and effective patient care. JAMA. 1997;278:502-509.

37. Torío J, García MC. The clinical interview and the patient-physician relationship: opinions and preferences of consumers. Aten Primaria. 1997; 19:44-60.

38. Torío J, García MC. The clinical interview and the patient-physician relationship: opinions and preferences of consumers. Aten Primaria. $1997 ; 19: 63-74$
39. Torio J, García MC. Evaluation of patient-orientation in primary care practice. Aten Primaria. 1997;20:45-55.

40. Candib L. Truth telling and advance planning at the end of life: problems with autonomy in a multicultural world. Fam Syst Health. 2002;20:213-228.

41. Slivinske LR, Fitch VL. The effect of control enhancing interventions on the well-being of elderly individuals living in retirement communities. Gerontologist. 1987; 27:176-181.

42. Quill TE, Brody H. Physician recommendations and patient autonomy: finding a balance between physician power and patient choice. Ann Intern Med. 1996;125:763-769.

43. Broggi MA. The relationship of solidarity in the clinic. A Mediterranean alternative. Homage to Lain Entralgo. JANO. 2000;1329:103-104.

44. Borrell-Carrió F, Prados JA. Bad News. Simple Strategies for Complex Situations. Barcelona: Doyma; 1995.

45. Tizón J. Componentes Psicológicos de la Práctica Médica: Una Perspectiva Desde la Atención Primaria [Psychological Components of Medical Practice]. Doyma: Barcelona; 1989.

46. Candib L. Working with suffering. Patient Educ Couns. 2002;48:43-50.

47. Emanuel EJ, Emanuel LL. Four models of the physician-patient relationship. JAMA. 1992;267:2221-2226.

48. Ubel PA. "What should I do, doc?": Some psychologic benefits of physician recommendations. Arch Intern Med. 2002;162:977-980.

49. Epstein RM, Morse DS, Williams GC, et al. Clinical practice and the biopsychosocial model. In: Quill TE, Frankel RM, McDaniel SH, eds. The Biopsychosocial Model. New York, NY: University of Rochester; 2002.

50. Borrell-Carrió F, Cebrià J. The helping relationship and the biopsychosocial model. In: Martín Zurro A, Cano F, eds. Atención Primaria. Madrid: Harcourt Brace; 1995.

51. Epstein RM, Mindful practice in action (II): cultivating habits of mind. Fam Syst Health. 2003;21:11-17.

52. Weick KM, Sutcliffe KM. Managing the Unexpected: Assuring High Performance in an Age of Complexity. San Francisco, Calif: Jossey-Bass; 2001.

52. Novack DH, Epstein RM, Paulsen RH. Toward creating physicianhealers: fostering medical students' self-awareness, personal growth, and well-being. Acad Med. 1999;74:516-520.

53. Epstein RM. Mindful practice in action I: technical competence, evidence-based medicine and relationship-centered care. Fam Syst Health. 2003;21:1-10

55. Santorelli, S. Heal Thy Self. Lessons on Mindfulness in Medicine. New York, NY: Bell Tower; 1999.

56. Dewey J. Experience and Nature. New York, NY: Dover; 1958.

57. Suzuki S. Zen Mind, Beginner's Mind. New York, NY: Weatherhill; 1980.

58. Dowrick C, May C, Bundred P. The biopsychosocial model of general practice: rhetoric or reality? Br J Gen Pract. 1996;46:105-107.

59. Haynes RB. BMC Health Services Research 2002. Available at http:// www.biomedcentral.com/1472-6963/2/3.

60. Borrell-Carrió F, Epstein RM. Preventing clinical errors: a call for selfawareness. Ann Fam Med. 2004:2:310-316.

61. Polanyi M. Personal Knowledge: Towards a Post-Critical Philosophy. Chicago, Ill: University of Chicago Press; 1974.

62. Schon DA. Educating the Reflective Practitioner. San Francisco, Calif: Jossey-Bass; 1987.

63. Epstein RM, Quill TE, Alper B. Communicating evidence for informed decision-making. JAMA. 2004;291:2359-2366.

64. James W. Pragmatism: A New Name for Some Old Ways of Thinking. New York, NY: Longmans Green; 1907.

65. Stacey RD. Complex Responsive Processes in Organizations: Learning and Knowledge Creation. London: Routledge; 2001. 